In press Nature 2014 (accepted 13 Jan 2014)

\title{
Global conservation outcomes depend on marine protected areas with five key features
}

Graham J. Edgar $^{1}{ }^{*}$, Rick D. Stuart-Smith $^{1}$, Trevor J. Willis ${ }^{2}$, Stuart Kininmonth ${ }^{1,3}$, Susan C. Baker ${ }^{4}$, Stuart Banks $^{5}$, Neville S. Barrett ${ }^{1}$, Mikel A. Becerro ${ }^{6}$, Anthony T.F. Bernard ${ }^{7}$, Just Berkhout ${ }^{1}$, Colin D. Buxton ${ }^{1}$, Stuart J. Campbell ${ }^{8}$, Antonia T. Cooper ${ }^{1}$, Marlene Davey ${ }^{1}$, Sophie C. Edgar ${ }^{9}$, Günter Försterra $^{10}$, David E. Galván ${ }^{11}$, Alejo J. Irigoyen ${ }^{11}$, David J. Kushner ${ }^{12}$, Rodrigo Moura ${ }^{13}$, P. Ed Parnell $^{14}$, Nick T. Shears ${ }^{15}$, German Soler ${ }^{1}$, Elisabeth M.A. Strain ${ }^{16}$, Russell J. Thomson ${ }^{1}$

${ }^{1}$ Institute for Marine and Antarctic Studies, University of Tasmania, GPO Box 252-49, Hobart, Tas 7001, Australia. Telephone: +61 3 62277277. Fax: 61362278035 Email:

g.edgar@utas.edu.au

${ }^{2}$ Institute of Marine Sciences, School of Biological Sciences, University of Portsmouth, Ferry Road, Portsmouth PO4 9LY, UK. Telephone: 442392845806 Email: trevor.willis@ @ort.ac.uk

${ }^{3}$ Stockholm Resilience Centre, Stockholm University, Kräftriket 2B, SE-106 91 Stockholm, Sweden, Telephone: +4686747070, email: stuart.kininmonth@ stockholmresilience.su.se

${ }^{4}$ School of Plant Science, University of Tasmania, GPO Box 252, Hobart, Tas 7001, Australia. Telephone: +61 36235 8306. Email: Sue.Baker@forestrytas.com.au

${ }^{5}$ Charles Darwin Foundation, Puerto Ayora, Galapagos, Ecuador. Telephone: (593) 5 2526-146, Email: stuart.banks@fcdarwin.org.ec

${ }^{6}$ The Bites Lab, Natural Products and Agrobiology Institute (IPNA-CSIC), 38206 La Laguna (Tenerife), Spain. Telephone: 34922256 847. Fax: 34922260112 Email: m.becerro@csic.es

${ }^{7}$ Elwandle Node, South African Environmental Observation network, Private Bag 1015, Grahamstown, 6140, South Africa. Telephone: 2746 6229899, Email: ant@saeon.ac.za

${ }^{8}$ Wildlife Conservation Society, Indonesia Marine Program, Jalan Atletik No. 8, Bogor Jawa Barat 16151, Indonesia. Telephone: +62 81111 71253, email: scampbell@wcs.org

${ }^{9}$ Department of Water, Perth, WA 6000, Australia. Telephone: +61 428198597 email: Sophie.Edgar@water.wa.gov.au

${ }^{10}$ Facultad de Recursos Naturales, Escuela de Ciencias del Mar, Pontificia Universidad Catolica de Valpara1so, Valparaiso, Chile. Phone: +56-65-280368 Fax: +49-8102-748591 Email: gunter_forsterra@yahoo.com

${ }^{11}$ Centro Nacional Patagonico, Consejo Nacional de Investigaciones Cientificas y Tecnicas, Bvd Brown 2915, (9120) Puerto Madryn, Argentina. Telephone: 54280 4451024. Fax: 54280 4451543. Email: galvan@cenpat.edu.ar

${ }^{12}$ Channel Islands National Park, United States National Park Service, 1901 Spinnaker Dr., Ventura, CA 93001, USA, Telephone: 808 658-5773, Email: david_kushner@nps.gov 
${ }^{13}$ Instituto de Biologia, Universidade Federal do Rio de Janeiro, Av. Carlos Chagas Filho 373, Rio de Janeiro, RJ, 21941-902, Brazil, Telephone: 55 (21) 9609-2724, Email:

moura@biologia.ufrj.br

${ }^{14}$ Scripps Institution of Oceanography, UC San Diego, Mail Code 0227, 9500 Gilman Dr., La Jolla, CA 92093-0227, USA, Telephone: 858 822-2701, Email: edparnell@ ucsd.edu

${ }^{15}$ Leigh Marine Laboratory, University of Auckland, New Zealand, Telephone: 6493737599. Email: n.shears@auckland.ac.nz

${ }^{16}$ Dipartimento di Scienze Biologiche, Geologiche ed Ambientali, Università di Bologna, Via San Alberto, Ravenna 163-48123, Italy, Telephone: +39 0544 937314, Fax: +39 0544 937303, Email: strain.beth@gmail.com

*Correspondence to: g.edgar@utas.edu.au

In line with global targets agreed under the Convention on Biological Diversity, the number of marine protected areas (MPAs) is increasing rapidly, yet socio-economic benefits generated by MPAs remain difficult to predict and under debate ${ }^{1,2}$. MPAs often fail to reach their full potential as a consequence of such factors as illegal harvesting, regulations that legally allow detrimental harvesting, or emigration of animals outside boundaries because of continuous habitat or inadequate size of reserve ${ }^{3-5}$. Here we show conservation benefits of 87 MPAs investigated worldwide increase exponentially with the accumulation of five key features - notake, well-enforced, old (>10 years), large $\left(>100 \mathrm{~km}^{2}\right)$, and isolated by deep water or sand. Using effective MPAs with four or five key features as an unfished standard, comparisons of underwater survey data from effective MPAs with predictions based on survey data from fished coasts indicate that total fish biomass has declined about two-thirds from historical baselines. Effective MPAs also had twice as many large (>250 mm total length) fish species per transect, five times more large fish biomass, and 14 times more shark biomass than fished areas. Most (59\%) of the MPAs studied had only one or two key features and were not ecologically distinguishable from fished sites. Our results show that global conservation targets based on area alone will not optimise protection of marine biodiversity. More emphasis is needed on better MPA design, durable management, and compliance, to ensure MPAs achieve their desired conservation value. 
A multitude of socio-economic and biological factors influence the responses of species to protection within MPA networks, adding considerable uncertainty when making specific predictions regarding the conservation benefits of new MPAs. Even within well-designed MPAs, populations of marine species can respond quite differently to prohibitions on fishing as a consequence of species-specific factors such as mobility, larval dispersal, fecundity, longevity, indirect interactions among species, environmental context, and overall level of exploitation prior to protection ${ }^{5,6}$. In order to assess the extent to which MPAs fulfil their ecological potential, we use a database unprecedented in geographic scale to investigate how conservation value, characterised by ecological response of fish communities within MPAs, is affected by the cumulative effects of five key planning and management features: (i) degree of fishing permitted within MPAs, (ii) level of enforcement, (iii) MPA age, (iv) MPA size, and (v) presence of continuous habitat allowing unconstrained movement of fish across MPA boundaries ${ }^{6-10}$. While previous studies have considered these factors independently, this is the first to consider them simultaneously, using data collected globally with standardised methods.

Observations from the subset of MPAs that appear to work effectively, in that they include at least four of five 'NEOLI' (no-take, enforced, old, large, and isolated) features, are additionally used to infer ecological condition associated with unfished reefs. For this aspect, we utilise the global network of MPAs as a vast ecological experiment, where effective no-take areas represent human predator exclusion plots within a matrix of fished coasts ${ }^{11}$.

Eight community-level metrics were assessed using data from 40 nations on shallow reef fish densities and sizes provided by researchers and trained volunteer divers participating in the Reef Life Survey (RLS) program ${ }^{12}$. A total of 964 sites in 87 MPAs were surveyed (Extended Data Fig. 1a), with data aggregated into $121 \mathrm{MPA} /$ ecoregion groupings for analysis. MPA means were compared with statistical predictions for fished coasts using data from 1,022 non-MPA sites surveyed in 76 of the 232 Marine Ecoregions of the World ${ }^{13}$ (Extended Data Fig. 1b; Supplementary Data Table 1). The four community metrics investigated, each widely considered to respond to MPA declaration ${ }^{14,15}$, were: (i) total biomass of all fishes, (ii) total biomass of large (>250 mm length) fishes, (iii) species richness of all fishes (number of species sighted per transect), and (iv) species richness of large fishes. We also estimated the total biomass of three 
commercially-important taxa (sharks, groupers and jacks), with unexploited damselfishes providing a control group for effects evident on targeted fishery groups. Effect size was calculated using the log ratio of measured values in MPAs relative to values predicted using global models for fished coasts.

Amongst 14 environmental and socio-economic covariates used to develop models for fished coasts, mean sea surface temperature, annual temperature range, photosynthetically-active radiation, and latitude consistently exerted the strongest influence on the global distribution of species richness and biomass metrics (Extended Data Fig. 2). Biomass of groupers and jacks were also greatly influenced by human population density, and sharks and groupers by phosphate concentration.

Fish species richness along fished coasts peaked in the southeast Asian 'Coral Triangle' region (Fig. 1a), as expected ${ }^{12,16}$. However, when only the number of large fishes sighted along transects was considered (Fig. 1b), the global centre of species richness shifted to more isolated locations within the Indo-Pacific region. Overfishing of large predatory fishes presumably contributed to these geographic patterns. Sharks, groupers and other large fishes were present within the Coral Triangle region but exploited to near absence on most reefs, so rarely recorded on transects; consequently, observed species richness of large fishes was relatively low.

Our predictive models indicated that total fish and large fish biomass were highest in French Polynesia and the nearby Line Islands (Figs 1c,d), while sharks, groupers and jacks also had disproportionally high biomass in that region (Extended Data Figs 3a, b, c). Shark biomass on fished coasts was also very high off the Pitcairn Island group, and north-eastern and northwestern Australia. Reassuringly, high shark and grouper biomass were accurately predicted for Galapagos, regardless that no data from fished sites in the oceanic tropical eastern Pacific region were used to generate the predictive models. At the time of surveys, all islands in the region (Galapagos, Cocos and Malpelo) were within MPAs; however, data obtained prior to fishing restrictions in Galapagos indicates anomalously high shark and grouper biomass for fished coasts in that archipelago (SB, GJE, unpublished data). Damselfishes occurred in relatively high abundance in all tropical ocean basins (Extended Data Fig. 3d). 
Across all 87 MPAs investigated, species richness of large fishes was 36\% greater inside MPAs compared to fished areas (95\% confidence limits: 16\%-60\% increase), biomass of large fishes was 35\% greater (CL 3\%-78\% increase) and sharks 101\% greater (CL 17\%2-39\% increase). Nevertheless, for species richness of all fishes and the other four biomass metrics investigated, no significant difference ( $p>0.05$ ) was found between levels observed in MPAs and those predicted for fished coasts. Moreover, many MPAs possessed fish biomass well below predicted regional averages, as indicated by the large percentage of MPAs with negative log ratios for total biomass, ranging from $25 \%$ of MPAs for large fishes to $31 \%$ for sharks to $47 \%$ for groupers. These negative values indicate considerable site-scale variability in fish densities, with some MPA sites exhibiting low fish biomass due to local habitat variability between survey sites and, in other cases, a bias resulting from stakeholder consultation processes prior to MPA declaration aimed at minimising lost fishing opportunity ${ }^{17}$.

The poor overall performance of MPAs worldwide in terms of recovery of fish biomass relative to fished sites was due to a high frequency of ineffective MPAs and high spatial variability in fish densities, rather than an absence of recovery in all MPAs. The efficacy of MPAs was strongly influenced by the five NEOLI planning and management features (no-take, enforced, old, large, and isolated), with MPAs that scored highly with multiple NEOLI features typically exhibiting highly elevated biomass of exploitable fishes compared to fished sites (Fig. 2). MPAs with at least four NEOLI features were distributed across six countries in three oceans (Extended Data Fig. 1a) and a range of environmental conditions, indicating that model outputs and conclusions were not strongly regionally biased.

No significant differences were evident between fished sites (zero features) and MPAs with one or two NEOLI features; however, effect sizes rose rapidly when the number of features increased from three to five (Fig. 2, Extended Data Fig. 4). For example, the measured rises in mean values within MPAs relative to fished areas for total fish biomass, total large fish biomass and shark biomass with three NEOLI features were 30\%, 66\%, and 104\%, respectively. These increases were, however, modest compared to values when all five NEOLI features were present, with massive $244 \%, 840 \%$, and $1990 \%$ increases, respectively. Similar dramatic increases in biomass 
were evident for groupers (882\%) and jacks (864\%). Non-fished damselfishes showed a smaller mean increase of $111 \%$ at MPAs with five NEOLI features. This increase was on the margins of statistical significance, lying outside the $95 \%$ confidence interval (Extended Data Fig. 4) but non-significant $(\mathrm{p}<0.05)$ when assessed with a t-test, which adjusts for small sample size.

All four MPAs with five NEOLI features were small oceanic islands (Cocos, Costa Rica; Malpelo, Colombia; Kermadec Islands, New Zealand; and Middleton Reef, Australia), raising a potential concern that calculated effect sizes were biased by plankton and pelagic fish subsidies that enlarge food webs at isolated oceanic locations. 'Oceanic island' was, however, included as a categorical covariate in random forest models, consequently model predictions should accommodate small island effects. Regardless, further investigation into the contribution of external subsidies to food webs at isolated MPAs is warranted. Alternative explanations for elevated damselfish numbers in the most effective MPAs compared with poorly-protected MPAs include reduced fishing-related habitat deterioration such as dynamite damage to coral, and trophic cascades involving smaller predators that consume damselfishes and are prey to sharks and groupers.

No-take regulations, efficient enforcement, large area $\left(>100 \mathrm{~km}^{2}\right)$, and old age (>10 yr) each contributed similar increases in fish biomass within MPAs (Fig. 2). However, isolation, a categorical factor that distinguished MPAs with reef habitat surrounded by deep (>25 $\mathrm{m})$ water or large expanses of sand from MPAs with shallow reef habitat extending to fished areas, appeared to exert a stronger influence for community level biomass and richness metrics than the other four features. For example, the mean increase (95\% CI) for total fish biomass associated with MPAs with three NEOLI features was 100\% (14\% - 252\%) when one of the three features was isolation, compared to $14 \%(-18 \%-58 \%)$ for three NEOLI MPAs when isolation was not included. Compliance may have contributed to the isolation effect, in that isolated MPAs are generally well demarcated for control purposes. They are readily recognised by fishers and more easily policed than coastlines with complicated mosaics of no-take, restricted take, and fishing zones. While very important, the effect of isolation was similar in magnitude rather than clearly superior to other MPA features for biomass of sharks, groupers and jacks (Extended Data Fig. 4). 
When MPAs that are no-take and well-enforced are considered, differences were evident in how the other MPA features affect different components of the fish community (Fig 3, Extended Data Fig. 5). Total fish biomass increased significantly from low to high levels for all five MPA features, and these same trends were magnified for large fishes (Fig 3). Regardless of general concerns that large pelagic species move such great distances that few individuals are fully protected within MPAs ${ }^{18}$, sharks and jacks appear to receive considerable protection from fishing mortality within the large, well-enforced, no-take MPAs studied here. The biomass of sharks and groupers rose exponentially when MPAs were fully isolated, and also greatly increased with area and age. Jacks showed little isolation and age effects, but rose greatly in MPAs that were large, well-enforced and no-take. Damselfish biomass did not increase significantly with the accumulation of individual NEOLI features.

The large number of MPAs investigated here has allowed relatively subtle and higher order interactive MPA effects to be detected. Previous studies of MPAs have shown, for example, negligible or weak patterns associated with MPA size ${ }^{6,9,14,15,19}$, and those detected here were only evident for MPAs with at least three of the NEOLI features. However, MPA size was very important for such metrics as jack biomass, which showed a stronger response to MPA area than to other metrics (Fig. 3). This response probably resulted from time spent by actively-swimming fishes outside park boundaries, which increases probability of capture for fishes associated with small MPAs.

Species richness of large fishes exhibited a highly significant difference between MPAs with five NEOLI features and fished locations (115\% increase relative to predicted; CI $95-137 \%$; $\mathrm{t}$-test, $P$ $<0.0001$; Fig. 2). By contrast, MPAs with five NEOLI features did not differ significantly in total species richness (6\% increase relative to predicted) from fished locations (t-test, $P=0.42$; Fig. 2), nor did any of the five features individually have a clear effect on species richness (Fig. 3). Thus, total species richness along transects did not detectably increase in effective MPAs, despite the presence of additional large fish species, perhaps because of food web changes in the form of reduced presence of small fish species that comprised prey of the larger predatory species ${ }^{5,20,21}$. Regardless of these transect-scale effects, species richness at regional scales likely 
increased in areas with a mosaic of fished and effective MPAs because of the additional presence of large fishery-targeted species within the seascape ${ }^{17}$.

Of the 87 MPAs investigated, only four possessed all five NEOLI features, while five MPAs possessed four features, and 40, 55, and 16 MPAs possessed three, two, and one feature, respectively. The low proportion of MPAs possessing four or five NEOLI features (10\%), and thus regarded here as effective, probably overstates the true proportion of effective MPAs worldwide. Our survey strategy deliberately targeted well-known and well-regarded MPAs, with most large and long-established MPAs included in this study.

While only a small subset of MPAs are ever likely to qualify as large, most MPAs could achieve the remaining four NEOLI features. MPAs require additional time to age, and sufficient will amongst stakeholders, managers and politicians for increased implementation of no-fishing zones, increased levels of compliance, and extension of boundaries past the limits of reef systems or to deep-water. If these could be achieved in tandem with current trends for declaration of large remote "wilderness" MPAs ${ }^{22,23}$, then conservation benefits from the global MPA network should increase markedly. However, the current base is very low with only $0.08 \%$ of the world's oceans within no-take MPAs in $2008^{24}$, and with opportunities for an expanded network diminishing as establishment and opportunity costs for large isolated MPAs escalate in line with human population growth ${ }^{23,25}$.

By using effective MPAs as an unfished standard, our study allows the first global assessment of the magnitude of fishing effects on temperate as well as tropical reef communities. Fish biomass was greatly reduced overall, with $63 \%$ of all fish biomass, $80 \%$ of large fish biomass, $95 \%$ of sharks, $84 \%$ of groupers, and $85 \%$ of jacks apparently removed from reefs by fishing.

In spite of their huge magnitude, these estimates are nevertheless likely to be conservative because they are based on the assumption that MPAs with four or five NEOLI features provide an accurate non-fished baseline for inferring historical patterns. Yet fish populations are unlikely to have fully recovered from previous impacts of fishing in four NEOLI MPAs, which were found to be less effective than five NEOLI MPAs for some metrics. Moreover, high fishing 
mortality rates for sharks and wide-ranging predatory fishes outside MPAs will negatively influence total numbers within boundaries through reduced immigration rates, and further recovery of fish biomass within MPAs probably continues over much longer time spans than the 10 year threshold used here to define old MPAs ${ }^{17}$. On the other hand, our estimates for effective MPAs include uncertainty associated with the low number of effective MPAs surveyed, most notably for sharks as only five of the nine category 4 and 5 NEOLI MPAs had sharks present. Also, biomass may be overestimated because of diminished flee responses from divers of large fishes in well-enforced no-take MPAs ${ }^{26}$. Regardless, fishing clearly exerts a very large and ubiquitous impact on shallow reefs.

The $80 \%$ reduction in biomass of large fishes outside effective MPAs coincides with the threshold value used by IUCN to categorise species as Critically Endangered for Red List assessments ${ }^{27}$. While recognising that application of current Red List thresholds to exploited fish stocks remains contentious ${ }^{27}$, the high number of large-bodied species that together average $80 \%$ decline indicates innumerable threatened species likely exist, and that effective MPAs probably play a large role in safeguarding populations of many of these species ${ }^{4}$. Even nations with relatively well-managed fisheries have few sharks and other large predatory coastal fishes outside well-designed and mature MPAs. Given the huge scale of fishing impacts, increasing fish extinctions are likely to occur through this century unless a refugial network of effective MPAs exists to allow persistence of large-bodied species and associated predator-dominated food webs, and broad-scale fisheries management practices significantly improve ${ }^{28}$.

\section{Methods summary}

Surveys were based on Reef Life Survey methodology ${ }^{12,29}$, with support from volunteer SCUBA divers trained individually to scientific data collection standards. All fishes observed within $50 \mathrm{~m}$ x $5 \mathrm{~m}$ transect blocks were counted, and total fish lengths estimated, during swims on adjoining blocks up one side and down the other side of 50 m lines. Each transect was set along a depth contour, with two depth contours (mean 2.4) generally surveyed at each site. Sites located within 87 MPAs were investigated, with approximately half located in Australia (36) and New Zealand 
(8). In total, 48 MPAs were complete no-take, 18 MPAs allowed limited fishing, while 21 MPAs were multi-zoned with interspersed no-take and limited fishing zones. Data were compiled from 171,331 underwater abundance counts of 2,544 species in 9,544 transect blocks at 1,986 sites.

We assessed effects of five MPA features (fishing regulations, enforcement, age, area and isolation), each categorized at low, medium and high levels, on eight fish community metrics (species richness of all fishes and large $(>250 \mathrm{~mm})$ fishes; total biomass of all fishes, large fishes, sharks, groupers, jacks and damselfishes). The magnitudes of effects were quantified using the log ratio of observed value within the MPA to predicted value at that location if the MPA did not exist (e.g., $\log \left(B_{m} / B_{p}\right)$, where $B_{m}$ is measured fish biomass and $B_{p}$ is biomass predicted if the site was fished). Predictions were produced using random forest procedures ${ }^{30}$, where each forest was created by generating 2,000 regression trees from a bootstrap sample of the data. Relationships were initially established between 14 covariates (environmental and socioeconomic) and measured values of the eight response metrics at fished sites. These relationships were then used, with known covariate values at each MPA, to predict each of the eight community metrics at that MPA location.

1 Hilborn, R., Micheli, F. \& De Leo, G. A. Integrating marine protected areas with catch regulation. Canadian Journal of Fisheries and Aquatic Sciences 63, 642-649 (2006).

2 Gell, F. R. \& Roberts, C. M. Benefits beyond boundaries: the fishery effects of marine reserves. Trends in Ecology and Evolution 18, 448-455 (2003).

3 Edgar, G. J. Does the global network of marine protected areas provide an adequate safety net for marine biodiversity? Aquatic Conservation: Marine and Freshwater Ecosystems 21, 313-316 (2011).

4 Mora, C. et al. Coral reefs and the global network of Marine Protected Areas. Science 312, 17501751 (2006).

5 Babcock, R. C. et al. Decadal trends in marine reserves reveal differential rates of change in direct and indirect effects. Proceedings of the National Academy of Sciences of the United States of America 107, 18251-18255 (2010).

$6 \quad$ Claudet, J. et al. Marine reserves: size and age do matter. Ecology Letters 11, 481-489 (2008).

7 Guidetti, P. et al. Italian marine reserve effectiveness: Does enforcement matter? Biological Conservation 141, 699-709 (2008).

8 Le Quesne, W. J. F. Are flawed MPAs any good or just a new way of making old mistakes? ICES Journal of Marine Science 66, 132-136 (2009).

9 Vandeperre, F. et al. Effects of no-take area size and age of marine protected areas on fisheries yields: A meta-analytical approach. Fish and Fisheries 12, 412-426 (2011). 
Forcada, A., Bayle-Sempere, J. T., Valle, C. \& Sanchez-Jerez, P. Habitat continuity effects on gradients of fish biomass across marine protected area boundaries. Marine Environmental Research 66, 536-547 (2008).

11 Walters, C. J. \& Holling, C. S. Large-scale management experiments and learning by doing. Ecology 71, 2060-2068 (1990).

12 Stuart-Smith, R. D. et al. Contrasting global patterns of species and functional diversity in reef fishes. Nature 501, 539-542 (2013).

13 Spalding, M. D. et al. Marine ecoregions of the world: a bioregionalization of coastal and shelf areas. Bioscience 57, 573-583 (2007).

14 Côté, I. M., Mosqueira, I. \& Reynolds, J. D. Effects of marine reserve characteristics on the protection of fish populations: a meta-analysis. Journal of Fish Biology 59 (Suppl. A), 178-189 (2001).

15 Halpern, B. S. The impact of marine reserves: Do reserves work and does reserve size matter? Ecological Applications 13 (Suppl), 117-137 (2003).

16 Roberts, C. M. et al. Marine biodiversity hotspots and conservation priorities for tropical reefs. Science 295, 1280-1284 (2002).

17 Edgar, G. J., Barrett, N. S. \& Stuart-Smith, R. D. Exploited reefs protected from fishing transform over decades into conservation features otherwise absent from seascapes. Ecological Applications 19, 1967-1974 (2009).

18 Grüss, A., Kaplan, D. M., Guénette, S., Roberts, C. M. \& Botsford, L. W. Consequences of adult and juvenile movement for marine protected areas. Biological Conservation 144 692-702 (2011).

19 Guidetti, P. \& Sala, E. Community-wide effects of marine reserves in the Mediterranean Sea. Marine Ecology Progress Series 335, 43-56 (2007).

20 Graham, N. A. J., Evans, R. D. \& Russ, G. R. The effects of marine reserve protection on the trophic relationships of reef fishes on the Great Barrier Reef. Environmental Conservation 30 200-208.

21 Willis, T. J. \& Anderson, M. J. Structure of cryptic reef fish assemblages: Relationships with habitat characteristics and predator density. Marine Ecology Progress Series 257, 209-221 (2003).

22 Pala, C. Giant marine reserves pose vast challenges. Science 339, 640-641 (2013).

23 Graham, N. A. J. \& McClanahan, T. R. The Last Call for Marine Wilderness? BioScience 63, 397402 (2013).

24 Wood, L. J., Fish, L., Laughren, J. \& Pauly, D. Assessing progress towards global marine protection targets: shortfalls in information and action. Oryx 42, 1-2 (2008).

25 Mora, C. et al. Global human footprint on the linkage between biodiversity and ecosystem functioning in reef fishes. PLoS Biology 9, e1000606 (2011).

26 Cole, R. G. Abundance, size structure, and diver-oriented behaviour of three large benthic carnivorous fishes in a marine reserve in northeastern New Zealand. Biological Conservation 70, 93-99 (1994).

27 IUCN Standards and Petitions Working Group. Guidelines for Using the IUCN Red List Categories and Criteria. Version 7.0., (Downloaded 18 Nov 2013 from http://intranet.iucn.org/webfiles/doc/SSC/RedList/RedListGuidelines.pdf, 2008).

28 Mora, C. \& Sale, P. F. Ongoing global biodiversity loss and the need to move beyond protected areas: a review of the technical and practical shortcomings of protected areas on land and sea. Marine Ecology Progress Series 434, 251-266 (2011).

29 Edgar, G. J. \& Stuart-Smith, R. D. Ecological effects of marine protected areas on rocky reef communities: a continental-scale analysis. Marine Ecology Progress Series 388, 51-62 (2009).

30 Breiman, L. Random forests. Machine Learning 45, 15-32 (2001). 
Supplementary Information is available in the online version of the paper.

Acknowledgments We thank the many Reef Life Survey (RLS) divers who contributed to data collection. Development of the RLS dataset was supported by the former Commonwealth Environment Research Facilities Program, while analyses were supported by the Australian Research Council, a Fulbright Visiting Scholarship (to GJE), the Institute for Marine and Antarctic Studies, and the Marine Biodiversity Hub, a collaborative partnership funded under the Australian Government's National Environmental Research Program. Surveys were assisted by grants from the National Geographic Society, Conservation International, Wildlife Conservation Society, Winifred Violet Scott Trust, Tasmanian Parks and Wildlife Service, the Winston Churchill Memorial Trust, University of Tasmania, and ASSEMBLE Marine. We remain extremely grateful to the many park officers who assisted permitting and field activities, and to numerous marine institutions worldwide for hosting survey trips.

Author contributions GJE and RSS conceived the idea; GJE, RSS, MAB, AB, SCB, SJC, ATC, MD, SCE, GF, DEG, AJI, SK, DJK, RM, GS, EMAS, and many others collected the data; GJE, RJT, TJW, SK and SCE analysed data and prepared figures; GJE drafted the initial manuscript with contributions from all authors.

Author Information Reprints and permissions information is available at www.nature.com/reprints. The authors declare no competing financial interests. Readers are welcome to comment on the online version of the paper. Ecological data are available from the authors on request. Correspondence and requests for materials should be addressed to g.edgar@utas.edu.au. 

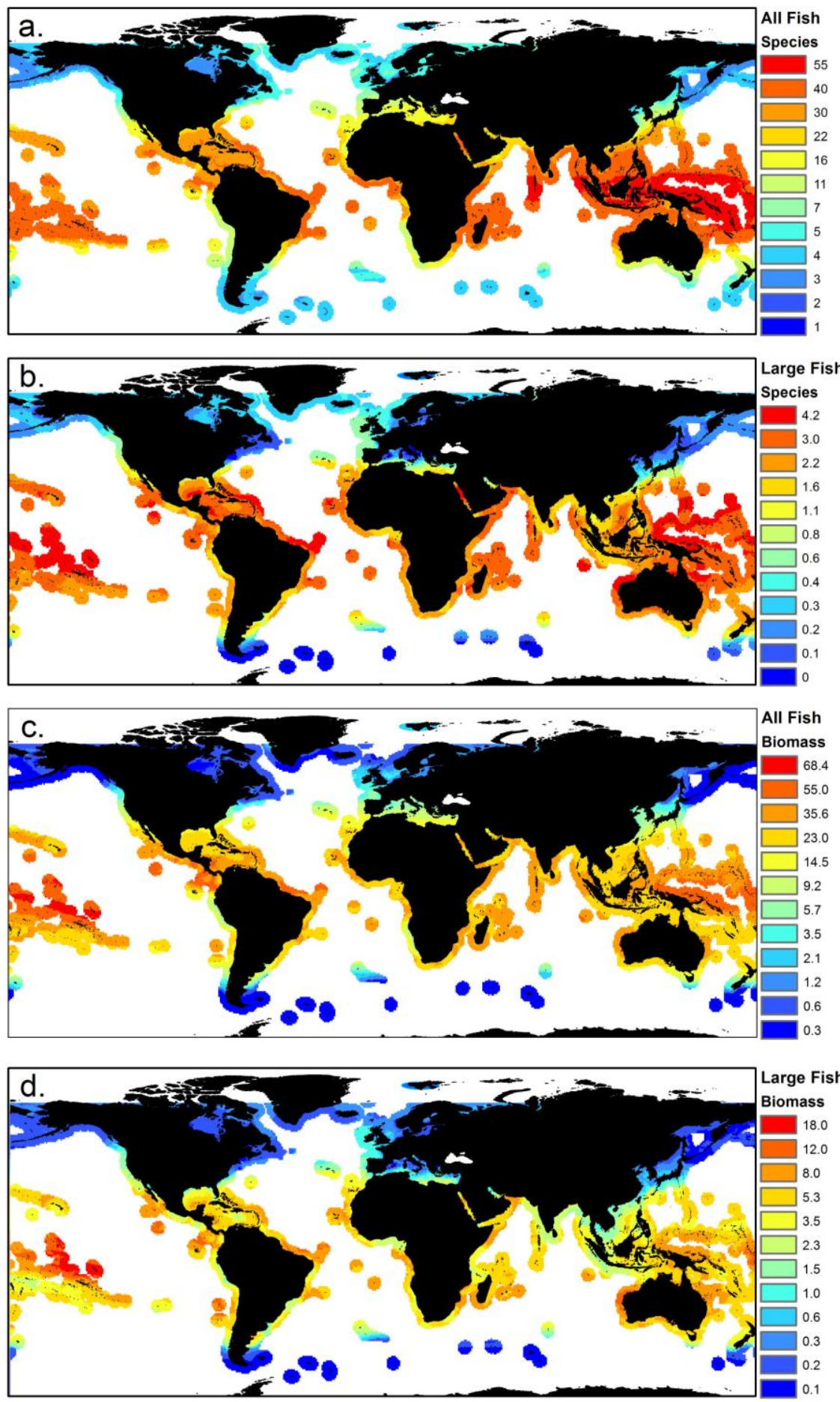

Figure 1 | Predicted global distribution of four community metrics for fishes associated with coral and rocky reefs outside of MPAs. Predictions are from random forest models parametrised with data from 1,022 sites in fished locations worldwide. a, Species richness of all fishes (number of species sighted per $250 \mathrm{~m}^{2}$ ). b, Species richness of large ( $>250 \mathrm{~mm}$ total length) fishes $\left(/ 250 \mathrm{~m}^{2}\right)$. c, Total biomass of all fishes $\left(\mathrm{kg} / 250 \mathrm{~m}^{2}\right)$. d, Total biomass of large fishes $\left(\mathrm{kg} / 250 \mathrm{~m}^{2}\right)$. 


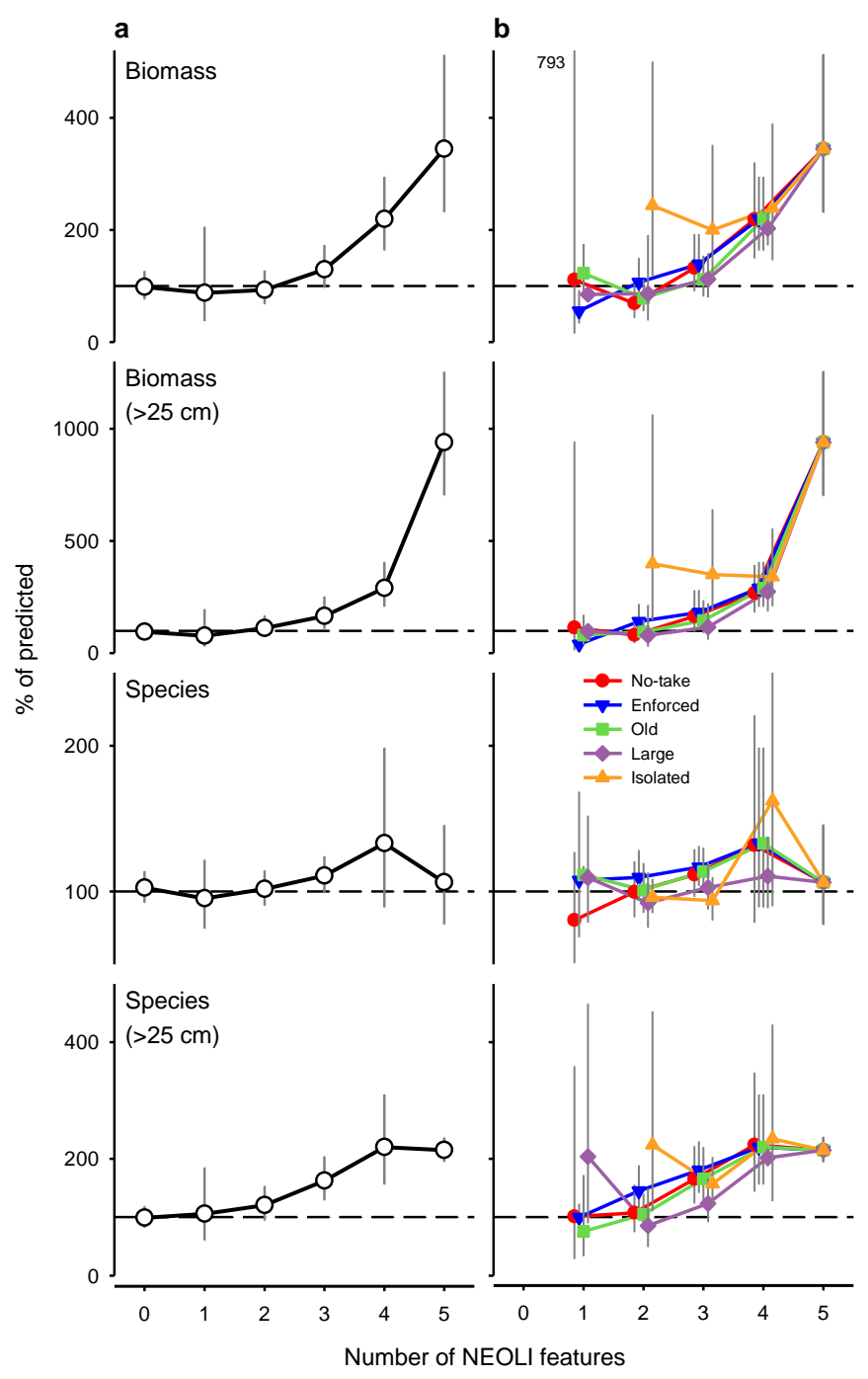

Figure 2 Mean response ratios for MPAs with different numbers of NEOLI (no-take, enforced, old, large, isolated) features. Mean ratio values have been back transformed from logs and expressed as percentages with $95 \%$ confidence intervals. Sites on fished coasts have 0 NEOLI features. a, Mean response ratios for four community metrics. b, Mean response ratios for community metrics where each NEOLI feature was included within the set examined. The 'no-take' plot with 2 features, for example, depicts the mean response for no-take MPAs with a single other NEOLI feature. 

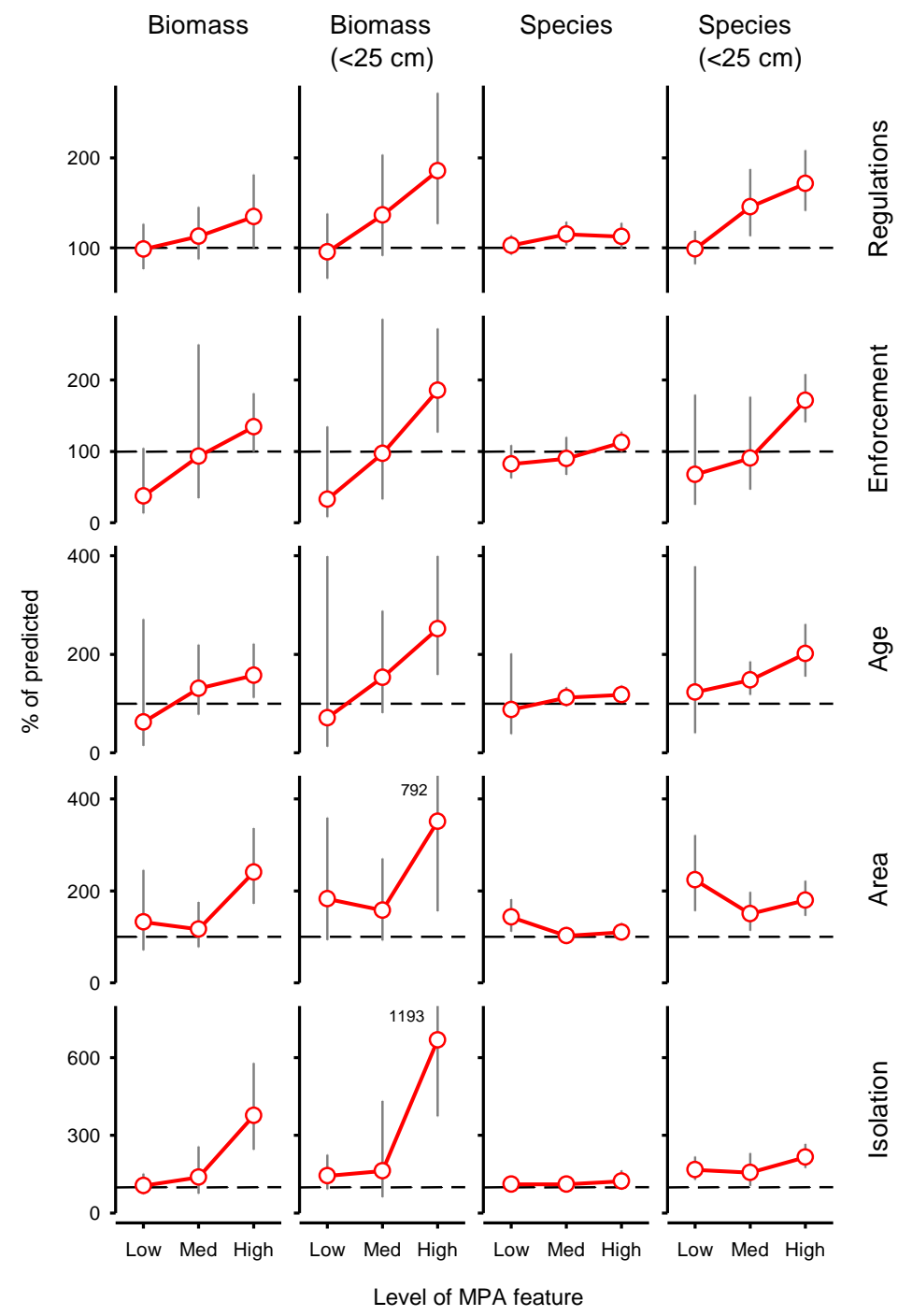

Figure 3 | Mean response ratios with $95 \%$ confidence intervals for four community metrics and low (L), medium (M), and high (H) levels of five MPA features. Values have been back transformed to percent scale, with $100 \%$ equivalent to fished coasts. The feature 'regulations' was analysed using data from 82 MPAs with high enforcement, the feature 'enforcement' using 75 MPAs that are no-take, and the features 'isolation', 'age' and 'area' using 52 MPAs that are both no-take and well-enforced. 


\section{METHODS}

Survey methodology. Standardised visual census counts were made at 1,986 sites using Reef Life Survey (RLS) methodology (see RLS methods manual 'Standardised survey procedures for monitoring rocky and coral reef ecological communities' at http://reeflifesurvey.com/files/2008/09/NEW-Methods-Manual_15042013.pdf). Divers made counts and estimates of total lengths of all fish species observed during swims at $\approx 2 \mathrm{~m} / \mathrm{s}$ along the centre of a $5 \mathrm{~m}$ wide swathe up one side and then down the other side of $50 \mathrm{~m}$ transect lines. Fishes sighted in transect blocks were recorded on an underwater slate, with abundance estimates made by counting individuals of less abundant species and, in locations with high fish densities, estimating the number of more abundant species. Abundances of schooling fishes were recorded by counting a subset within the school which was combined with an estimate of the proportion of the total school. Nearly all fishes were recorded to species level, with exceptions classified at the highest taxonomic resolution possible. The use of digital photography typically allowed later identification of most unidentified species, with assistance of taxonomic experts as required.

Experienced scientists and skilled recreational divers both contributed data to the RLS program, all divers having either substantial prior experience in fish surveys or extensive one-on-one training by RDSS or GJE. To provide a major element of consistency in diver contributions at the global scale, GJE and RDSS participated in most surveys, providing $31 \%$ of all data analysed. Validation tests indicated no difference in quality or composition of data provided by volunteers participating in this program when compared to professional biologists ${ }^{29}$.

Each transect was set along a depth contour, with two depth contours generally surveyed at each site (mean of 2.4 depths per site; minimum, maximum, mean \pm SD depth contours surveyed: 0.1 $\mathrm{m}, 42 \mathrm{~m}, 7.5 \pm 4.1 \mathrm{~m}$, respectively). Sites located within 87 MPAs were investigated, with approximately half located in Australia (36) and New Zealand (8). In total, 48 MPAs were notake where all fishing was prohibited, 18 MPAs allowed limited fishing, while 21 MPAs were multi-zoned with interspersed no-take and limited fishing zones. Data were compiled from 171,331 underwater abundance counts of 2,544 species in 9,544 transect blocks (50 m x $5 \mathrm{~m}$ ).

MPA features and community metrics investigated. We assessed influences of five MPA features on eight fish community metrics calculated using field survey data. The MPA features investigated were each categorised at three levels: low (L), medium (M) and high $(\mathrm{H})$ :

1. Regulations. Extent that regulations restrict fishing at survey site. L: site can be openly fished with no fishing restrictions additional to those generally applied within the state; M: site located within an MPA but with some fishing methods allowed; H: no-take area within an MPA.

2. Enforcement. Extent of compliance to regulations that restrict fishing, both through overt policing and through community support for regulations. Level was decided at the time of surveys following discussion with local park authorities, and on the basis of observations of the extent of infractions while conducting fieldwork. L: little attempt at control, a 'paper park'; M: a moderate level of policing attempted, although infractions were apparent; H: appears well enforced, although clandestine poaching may occur. 
3. Age. Period between when regulations restricting fishing were first enacted and field surveys undertaken. L: MPA zone <5 years old; M: MPA zone 5-10 years old; H: MPA zone $>10$ years old.

4. Area. MPA zone area, as described in management plan or documents provided locally to users. L: $<1 \mathrm{~km}^{2} ; \mathrm{M}: 1-100 \mathrm{~km}^{2} ; \mathrm{H}:>100 \mathrm{~km}^{2}$.

5. Isolation. Degree that reef habitat surveyed is isolated by habitat boundaries from adjacent fished reef. L: shallow $(<25 \mathrm{~m})$ reef habitat extends continuously across MPA boundary; M: a small (1-20\%) percentage of zone boundary breached by continuous shallow reef habitat; H: MPA zone isolated from fishing areas by depth (>25 m) or sand barriers of at least $20 \mathrm{~m}$ width.

Community metrics investigated comprised:

1. Species richness of all fishes. Total number of all fish species sighted within $50 \mathrm{~m} \times 5 \mathrm{~m}$ transect blocks.

2. Species richness of large fishes. Total number of fish species sighted within $50 \mathrm{~m} \times 5 \mathrm{~m}$ transect blocks for the set of individuals observed on transects exceeding the $250 \mathrm{~mm}$ size class bin (i.e. $300 \mathrm{~mm}$ size and above).

3. Total fish biomass. Total biomass of all fishes sighted in $50 \times 5 \mathrm{~m}$ transect blocks. Estimated by combining abundance counts with size estimates using length-weight relationships provided for total length of each fish species (in some cases genus and family) in Fishbase (http://www.fishbase.org). Bias in divers' perceptions of fish size underwater was additionally corrected using relationships presented in Edgar et al. ${ }^{31}$.

4. Total biomass of large fishes. Total biomass of individuals sighted in $50 \times 5 \mathrm{~m}$ transect blocks that exceeded the $250 \mathrm{~mm}$ size class bin.

5. Total biomass of sharks. Sum of biomass of all fishes in transect that belong to orders Carcharhiniformes, Heterodontiformes, Lamniformes, and Orectolobiformes.

6. Total biomass of groupers. Sum of biomass of all fishes in transect that belong to family Serranidae, genera Dermatolepis, Epinephelus, Gracila, Mycteroperca, Paralabrax, Plectropomus, Trachypoma, and Variola. Small serranids such as Pseudanthias spp. were not considered.

7. Total biomass of jacks. Sum of biomass of all fishes in transect that belong to family Carangidae.

8. Total biomass of damselfishes. Sum of biomass of all fishes in transect that belong to family Pomacentridae.

Data aggregation. In order to reduce spatial confounding resulting from highly clumped distribution of sites surveyed, data were aggregated prior to analyses as means for each ecoregion, MPA, and zone type. Thus, fished sites were aggregated as mean values for each of 76 Marine Ecoregions of the World ${ }^{13}$, while MPA data were aggregated into 121 MPA zone by ecoregion combinations. Multi-zoned MPAs contributed two data points to analyses (no-take sites and restricted fishing sites), while very large MPAs that extended across ecoregional boundaries (e.g. Great Barrier Reef Marine Park, Galapagos Marine Reserve) were also partitioned with aggregated data from each ecoregion.

Global models. Models were developed using random forest procedures ${ }^{30}$, as available in the 'extendedForest' packages for R (https://r-forge.r-project.org/projects/gradientforest), to predict 
the distribution of the eight community metrics in inshore habitats globally, including the MPA locations investigated. Each random forest consisted of numerous (2000 in this case) regression trees, where each tree is fit to a bootstrap sample of the biological data using a recursive partitioning procedure. Random forest analyses also contain cross validation routines based on random subsets of survey sites and covariate predictors that are excluded during development of each tree (the 'out-of-bag' data). Cross validation using out-of-bag data allow estimation of prediction performance $\left(\mathrm{R}^{2}\right)$.

Using random forests, relationships were identified between mean densities of different fish species observed per transect in 76 marine ecoregions ${ }^{13}$ and the global distribution of 14 environmental and socio-economic covariates (Extended Data Table 1). Data for each ecoregion were logged after aggregation as a mean of mean values for sites within each ecoregion, with a total of 1022 fished sites investigated overall. Ecoregions with a value of zero for a particular metric (e.g. grouper biomass in temperate locations) were removed from analysis and treated as missing values when generating predictive models associated with individual MPAs. To estimate prediction error, cross-validation was used where observations not selected in the bootstrap sample for a tree were compared to their predictions. The percent change in accuracy was measured to assess the importance of each predictor variable (Extended Data Fig. 2). This is the change in accuracy of the predictions between models that include or do not include a given covariate, where accuracy was measured by the mean of the residuals squared using the 'out-ofbag' data.

Linear least-squares regression of survey observations at fished sites with random forest predictions indicated the models provided a reasonable fit. $\mathrm{R}^{2}$ values for predicted versus observed plots were $63 \%, 38 \%, 80 \%$ and $64 \%$ for total biomass, large fish biomass, species richness and large fish species richness, respectively, while the percentages of observations > predictions were $46 \%, 46 \%, 53 \%$ and $54 \%$, so observed data were well balanced with an even scatter above and below predictions.

Relationships generated between response metrics and environmental covariates were combined with available data on environmental and socioeconomic covariates at 964 sites surveyed in 87 MPAs to predict each of the eight fish community metrics within each unique combination of MPA zone type (no-take or restricted fishing) and ecoregion. From generated random forests, predictions were made at new sites by taking the average of response metrics derived from each tree individually. MPA effects for each MPA zone type were then calculated using the log ratio of predicted/observed value (e.g., $\log \left(B_{m} / B_{p}\right)$, where $B_{m}$ is measured fish biomass and $B_{p}$ is biomass predicted if the site was fished). When no individuals of one of the four fish groups (sharks, groupers, jacks or damselfishes) were recorded within a particular MPA, then that MPA was excluded from calculations of effect size. Mean effect sizes and confidence intervals thus relate to the subset of sites where each of the various fish groups were observed.

Random forest models were also used to predict values of each metric for fished sites across 5 arc-minute grid cells globally, which were then plotted on maps within a coastal buffer. The calculations underlying random forest models used to generate global maps differed from calculations used to predict MPA values in two ways: (i) they were based on 10 rather than 14 environmental covariates, with government effectiveness, corruption, GDP and oceanic island 
not considered given their small contribution to models (Extended Data Fig. 2) and difficulty in compilation through the full global prediction space, and (ii) data for the four fish groups were $\log (\mathrm{x}+$ minimum value for metric) transformed before analysis and back transformed post hoc to compensate for the many zeros associated with global mapping predictions.

31 Edgar, G. J., Barrett, N. S. \& Morton, A. J. Biases associated with the use of underwater visual census techniques to quantify the density and size-structure of fish populations. Journal of Experimental Marine Biology and Ecology 308, 269-290 (2004).

32 CIESIN \& CIAT. Gridded Population of the World Version 3 (GPWv3), Center for International Earth Science Information Network and Centro Internacional de Agricultura Tropical. Socioeconomic Data and Applications Center (SEDAC). (Columbia University, 2005).

33 Silverman, B. W. Density estimation for statistics and data estimation. (Chapman \& Hall, 1986).

34 Kaufmann, D., Kraay, A. \& Mastruzzi, M. The Worldwide Governance Indicators : a summary of methodology, data and analytical Issues. World Bank Policy Research Working Paper no. 5431, Available at SSRN: http://ssrn.com/abstract=1682130 (2010).

35 Tyberghein, L. et al. Bio-ORACLE: a global environmental dataset for marine species distribution modeling. Global Ecology and Biogeography 21, 272-281 (2012). 


\section{Extended Data}

(see sep pdf file)

Extended Data Figure 1 | Distribution of sites surveyed. a, Number of NEOLI (no-take, enforced, old, large and isolated) features at MPAs investigated (coloured circles). MPAs with most NEOLI features are overlaid on top, consequently numerous MPAs with 1 and 2 features are not visible. MPAs with five NEOLI features are: (1) Cocos, (2) Kermadec Islands, (3) Malpelo, (4) Middleton Reef, and with four NEOLI features: (5) Elizabeth Reef, (6) Poor Knights Islands, (7) Ship Rock, (8) Tortugas, and (9) Tsitsikamma. b, All MPA and fished sites surveyed (black circles). Blue shading summarises the number of sites surveyed within each ecoregion.

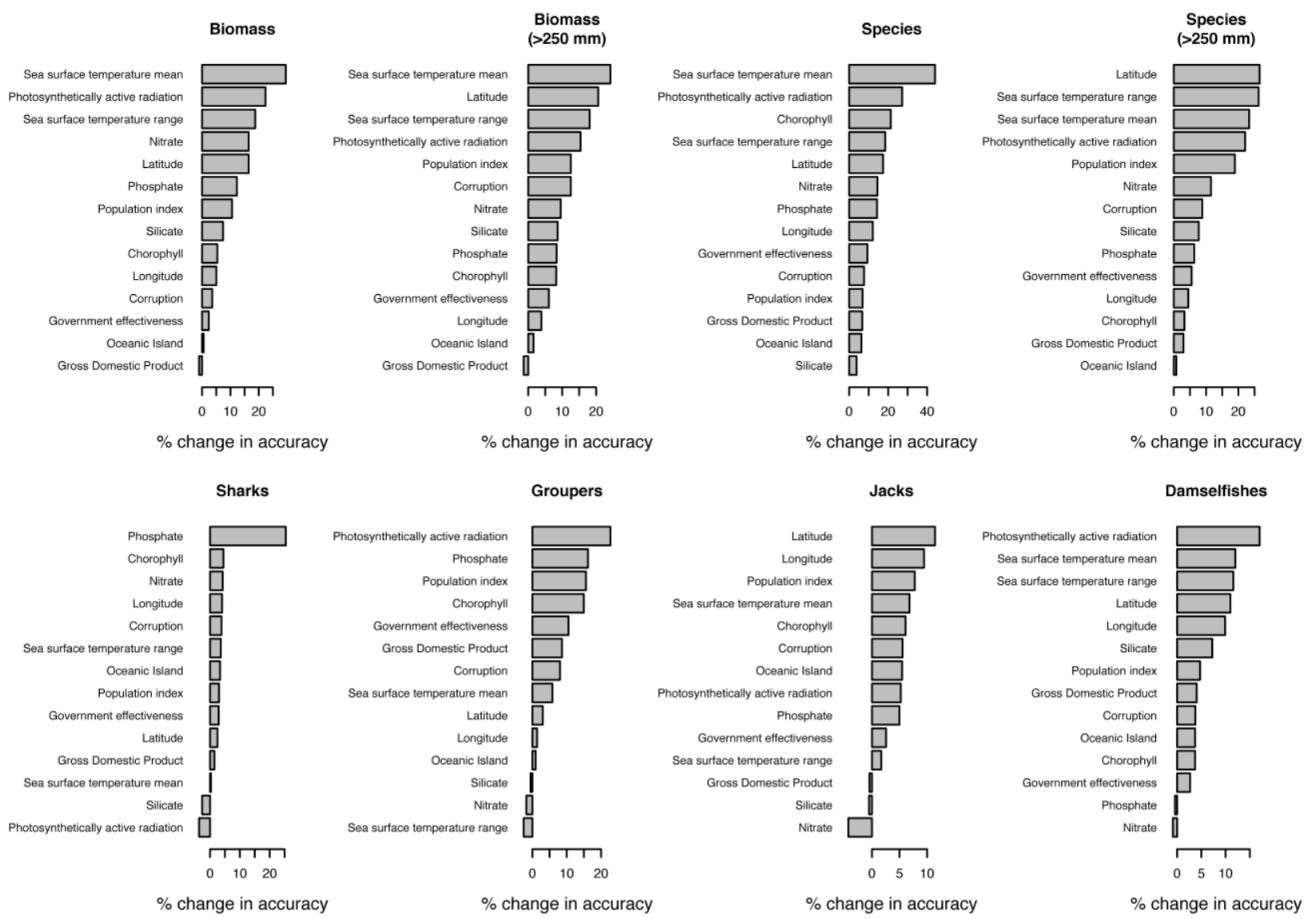

Extended Data Figure $2 \mid$ Relative importance of the 14 covariates used in global prediction models developed with random forests. Percent change in accuracy for a given predictor variable is measured by the change between models that include or do not include that predictor variable, with accuracy assessed as the mean of the residuals squared. Residuals are based on a cross validation technique to avoid bias, and the change in accuracy is divided by the standard error for a given tree then averaged across all trees. 

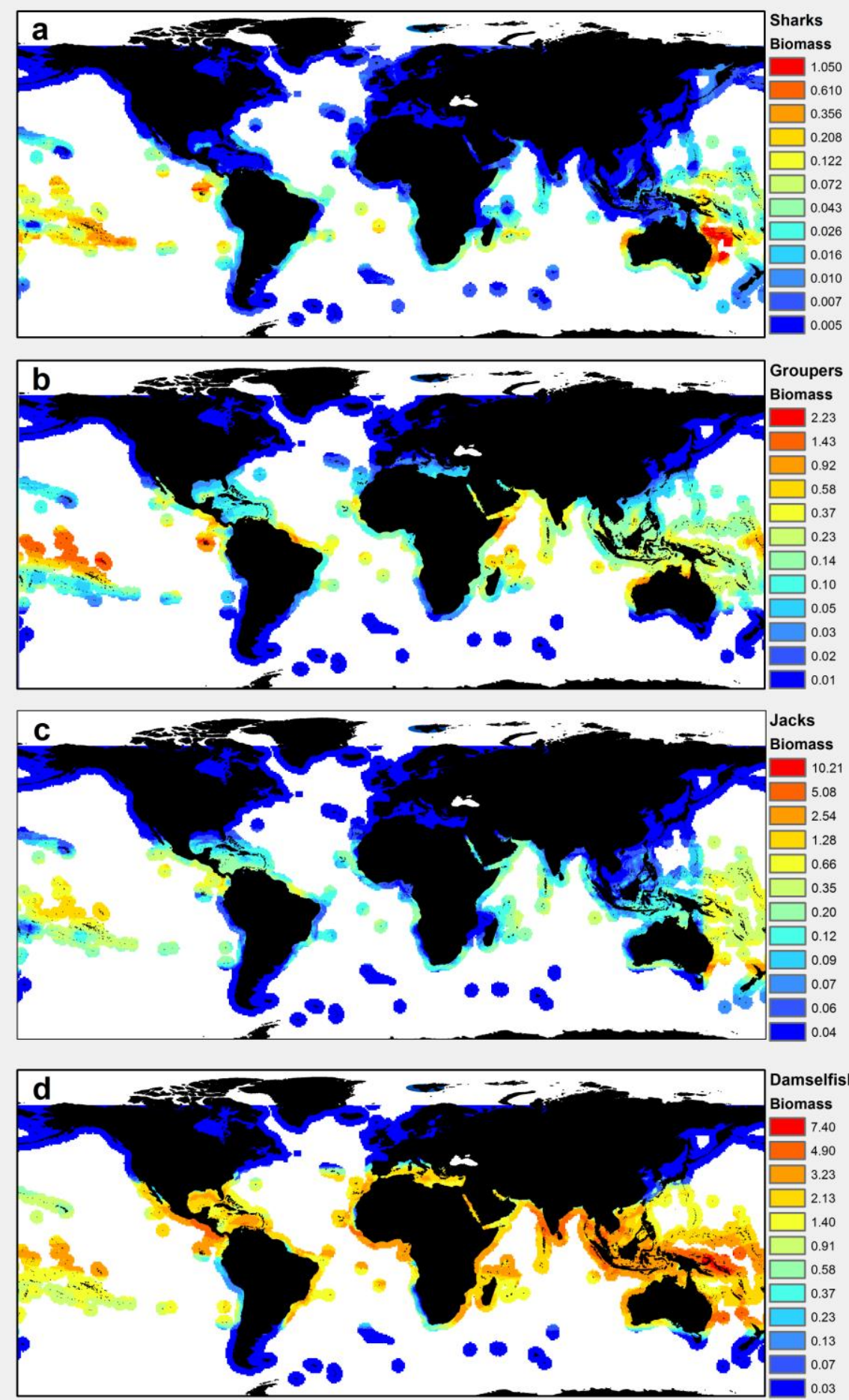

Extended Data Figure 3 | Predicted global distribution of fish biomass $\left(\mathrm{kg} / 250 \mathrm{~m}^{2}\right)$ on fished coasts. Predictions are from random forest models parametrised with data from 1,022 sites in fished locations worldwide. a, Sharks. b, Groupers. c, Jacks. d, Damselfishes. Note that scales in colour schemes differ among maps, and numbers represent predicted values represented by each colour after smoothing of log-transformed site-level data. 


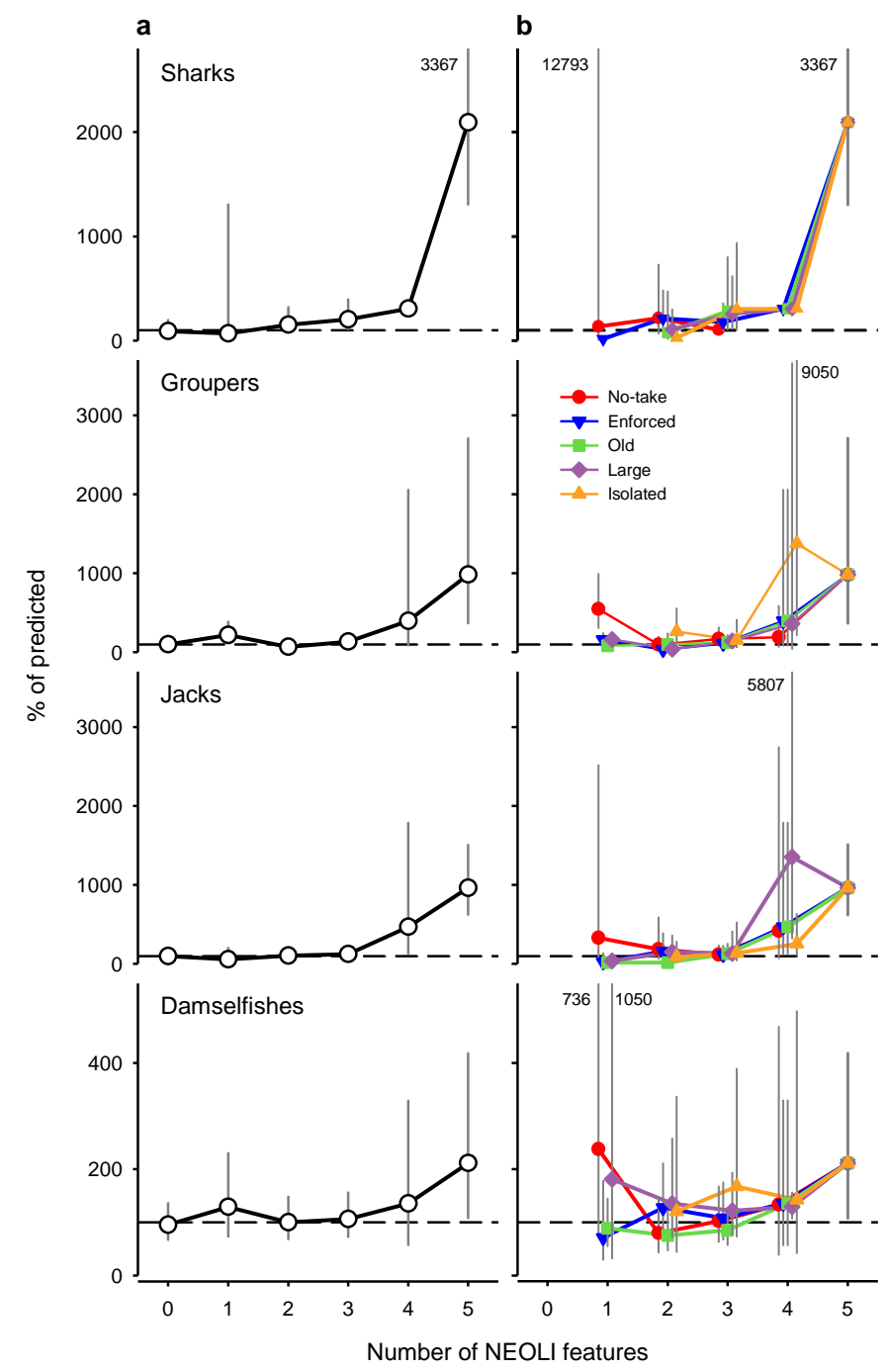

Extended Data Figure 4 | Mean response ratios for MPAs with different number of NEOLI features. Mean ratio values have been back transformed from logs and expressed as percentages with $95 \%$ confidence intervals. The number of NEOLI features varies from 0 at sites along fished coastlines to 5 for MPA sites with all NEOLI features. a, Plots calculated for sites where sharks, groupers, jacks and damselfishes were present and the subsets of MPAs with different numbers of NEOLI (no-take, enforced, old, large, isolated) features. b, Mean response ratios for community metrics where each NEOLI feature was included within the set examined. 

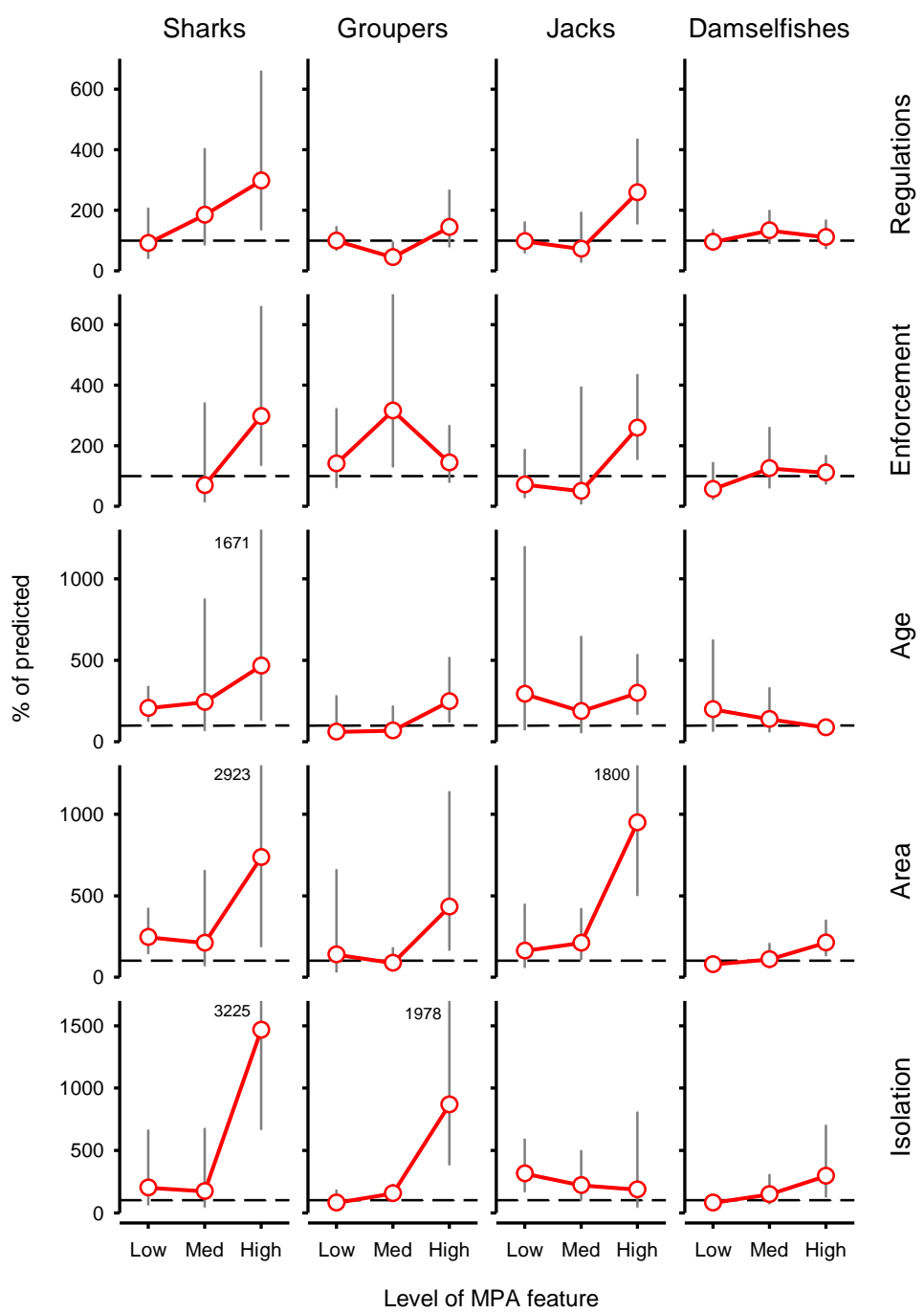

Extended Data Figure 5 | Mean response ratios for the subsets of sites at which sharks, groupers, jacks and damselfishes were observed. Values have been back transformed to percent, with $100 \%$ equivalent to fished coasts, and with $95 \%$ confidence intervals. The feature 'regulations' was analysed using data from 82 MPAs that are well-enforced, the feature 'enforcement' using 75 MPAs that are no-take, and the features 'isolation', 'age' and 'area' using 52 MPAs that are both no-take and well-enforced. Sharks were not observed in any no-take MPA with low enforcement, so the associated response ratio could not be calculated. 
Extended Data Table 1 | Covariates used as predictor variables in global random forest models. The index of population pressure was calculated by fitting a smoothly tapered surface to each settlement point on a year 2000 world population density grid ${ }^{32}$ using the quadratic kernel function described by Silverman ${ }^{33}$. Populations were screened for a density greater than 1000 people per 0.04 degree cell, and the search radius was set at 3.959 degrees. " Per capita GDP was obtained from IMF for 2012 at http:// http://en.wikipedia.org/wiki/List_of_countries_by_GDP_\%28PPP\%29_per_capita.

\begin{tabular}{|c|c|c|c|c|}
\hline Variable & Var abbrev & units & Scale & reference (if applicable) \\
\hline Index of population pressure & POP_index & index & $\begin{array}{l}2.46 \operatorname{arcmin}(4.6 \\
\mathrm{km})\end{array}$ & \\
\hline Government Effectiveness & Govt Eff & index & country & 34 \\
\hline Control of Corruption & Corruption & index & country & 34 \\
\hline Per capita GDP & GDP & US\$ & country & $\#$ \\
\hline Mean nitrate & Bio_nitrate & umol/l & $5 \operatorname{arcmin}(9.2 \mathrm{~km})$ & 35 \\
\hline Mean phosphate & BIO_phosphate & $\mathrm{umol} / \mathrm{l}$ & $5 \operatorname{arcmin}(9.2 \mathrm{~km})$ & 35 \\
\hline Mean silicate & BIO_silicate & umol/l & $5 \operatorname{arcmin}(9.2 \mathrm{~km})$ & 35 \\
\hline Mean chlorophyll A & BIO_chlomean & $\mathrm{mg} / \mathrm{m}^{3}$ & $5 \operatorname{arcmin}(9.2 \mathrm{~km})$ & 35 \\
\hline Photosynthetically active radiation & BIO_parmean & Einstein $/ \mathrm{m}^{3} /$ day & $5 \operatorname{arcmin}(9.2 \mathrm{~km})$ & 35 \\
\hline Mean sea surface temperature & BIO_SST_mean & ${ }^{\circ} \mathrm{C}$ & $5 \operatorname{arcmin}(9.2 \mathrm{~km})$ & 35 \\
\hline Range of sea surface temperature & BIO_SST_range & ${ }^{\circ} \mathrm{C}$ & $5 \operatorname{arcmin}(9.2 \mathrm{~km})$ & 35 \\
\hline $\begin{array}{l}\text { Oceanic island isolated from } \\
\text { continental shelf }\end{array}$ & Oceanic island & yes/no & & \\
\hline Site latitude & Latitude & decimal degrees & $0.0001^{\circ}$ & \\
\hline Site longitude & Longitude & decimal degrees & $0.0001^{\circ}$ & \\
\hline
\end{tabular}

